\title{
THE CONTROL OF BISCUIT LOSSES
}

\author{
By Ira E. Sproat
}

ABSTRACT

The effect of the transverse strength and the moisture content of the body on biscuit losses is discussed. A transverse strength of 280 pounds per square inch and minimum moisture content produce the best results.

The analysis of the damaged ware and the brushers report gives data of great value in decreasing the biscuit losses, under given factory conditions.

\section{Introduction}

The subject of biscuit loss and its control is one of great importance to the average general ware manufacturer; especially is this true during the present period of keen competition and the downward trend of selling prices.

The Human Element.--Perhaps the most important factor affecting the biscuit losses is the "Human Element." It has become increasingly important during the last five years due to the demand for production. But one needs only to read the discussion of Herford Hope's paper on "Biscuit Losses" 2 to learn that the "Human Element" was also a very important factor in 1906 as it now is. In fact it will always be an important factor. It is quite evident, therefore, that any method of control must take the "Human Element" very largely into consideration if it is to prove of any value.

After trying a number of different methods of control during the year 1919, we finally decided on the following three-fold control:

1. Transverse Strength of Body in the Clay State.

2. Biscuit Loss Analysis.

3. Analysis of Brushers Report.

During the past two years this method has been followed closely and we are certain the results have justified its use.

\section{Transverse Strength of Body}

It has always been a well known fact by potters that one of the best ways to decrease the biscuit losses is to increase the amount of ball clay in the body. The strength of the body in the clay state is thus increased and the effect of careless handling of the ware (the Human Element) decreased. There is, however, no published data on the relative effect of the varying strengths of bodies upon the biscuit losses. We thought it advisable to determine the modulus of rupture of our body for a period of several years and then compare these results with the biscuit losses for the same period, in order to determine what relation the one had to the other.

${ }^{1}$ Received May 10, 1922.

2 Trans. Amer. Ceram. Soc., 8, 62, 1906. 
Transverse strength tests of the body direct from the pug mill were made twice a week, the average of these two tests being taken as the weekly value. The results of these tests for the past three years are shown on the upper curve of the accompanying curve sheet.

The biscuit loss in per cents is also given for the same period on the same curve sheet; the fine dotted line represents the daily losses, while the lower heavy line, the weekly averages.

When studying these curves it must be remembered that the modulus of rupture curve is several weeks in advance of the biscuit loss curve, due to the time required to make the ware and put it through the biscuit kiln.

From the 22nd week of 1919 to the 30th week in 1921 inclusive the following body was used:

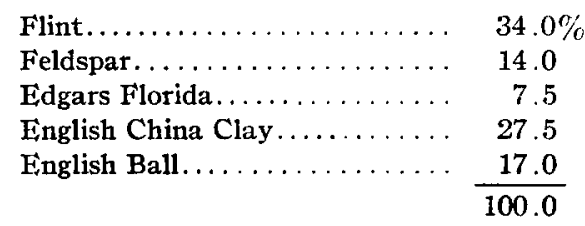

The great variation in strength of this body during the above period was due to the use of several kinds of English Ball clays and also to marked variations in the physical properties of different shipments of the same clay.

Specific attention is called to the high strength ( 300 pounds per sq. in.) of the body during the latter part of 1921 . This was due to the substitution of 21\% of "Hercules" clay for a portion of the English Ball and China clays in the formula just given. The maximum transverse strength obtained with English clays was only 260 pounds per square inch. Perhaps greater strengths could be obtained with these clays but color would have to be sacrificed and warpage would be materially increased.

From a study of the modulus of rupture and biscuit loss curves it can be readily seen that the biscuit losses decrease with every marked increase in strength up to 300 pounds, and vice versa. Therefore, decided changes in the modulus of rupture of a body is a sure indication that there will be an inverse change in the biscuit losses within a week or so, all other factors being equal.

From a further study we see that a modulus of rupture of 200 pounds will give a biscuit loss of about $7.0 \% ; 225$ pounds, a loss of about $6.0 \%$; 250 pounds, a loss of $5.0 \%$; 275 pounds a loss of $4.0 \%$; and 300 pounds, a loss of about $3.5 \%$. In other words the biscuit loss can be decreased about $1.0 \%$ by increasing the transverse strength 25 pounds per square inch, or $2.0 \%$ by a 50 pound increase in the strength, etc.

We also found that a body with a modulus of rupture of over 300 pounds 
had poor working qualities. It was too tough to flow readily when batted out or when formed into a piece of ware by the jiggerman, therefore, causing a greater biscuit loss than in a body having less strength.

The writer is of the opinion that a modulus of rupture of 280 pounds per square inch will give the best results under all conditions of manufacture. It must be remembered, however, that under some factory conditions, especially in those plants where quantity production is of secondary consideration, a modulus of rupture of 280 pounds will produce a biscuit loss far below the $3.5 \%$ noted above. In other words in those factories where more time and care is taken in handling the ware, a biscuit loss of $1.0 \%$ to $2.0 \%$ is no mere dream.

\section{Moisture Content}

Another factor to be considered is the amount of moisture the ware contains when it is removed from the molds. For a piece of ware which has a transverse strength of 300 pounds per square inch in the bone dry state, has a strength of only about 180 pounds when it contains from $3.0 \%$ to $10.0 \%$ moisture. All the moisture therefore would be expelled from the ware before it is handled.

Since very little ware being made today contains less than $3.0 \%$ of moisture, there is a great need for improved types of stove rooms in the general ware industries.

\section{Biscuit Loss Analysis}

Any method devised for the purpose of analyzing the damaged ware from the biscuit kilns, must necessarily meet the following three principal requirements.

First.- - It must not require too much time as it is advisable to make an analysis daily. All the damaged ware from the kilns can not be inspected daily, as this would require too much time. Only one class of ware should be analyzed daily.

Second.-The analysis should be made on that class of ware which is coming through the kilns daily in large quantities and in which the biscuit loss is the highest on the average. Seven-inch plates fill these requirements.

Third.-The classification of the various types of damages should be such that there would be no question as to how the damaged piece should be classified. After careful study and testing for months we have found the following classification satisfactory for this analysis:

1. Nipped

2. Warped

3. Rim Cracked

4. Foot Cracked 


\section{Bottom Cracked}

6. Dunted

7. Sympathetic Dunts

The above classification may be further simplified by combining 3 , 4 and 5 into one group called clay cracks.

It is not the purpose of this report to discuss the great number of different types of cracks and their causes, but in order that the reader may more fully understand the above classification a brief description of each type is given.

1. Nipped.-A piece of ware is classed as "nipped" if it is not cracked or warped. Cause.-Careless handling.

2. Warped.-All ware not cracked but warped is classed in this group. Cause.-Too high a ball clay content, too high and rapid firing.

3. Rim Cracked.-A piece of ware is classified under this heading if the crack is wider at the rim of the plate than in any other portion. Cause. -Too weak a body: Careless handling.

4. Foot cracks.-Cracks which show a greater width at the foot of the piece of ware are called footcracks. Cause.- Too weak a body, or careless handling; too green when taken off molds.

5. Bottom Cracked.-A plate which is cracked in the bottom is classed in this group. Cause.--Too weak a body; careless handling, or too green when taken off the molds.

6. Dunted.-A piece of ware is classed as dunted when it shows a fine circular hair line crack and the entire surface of the crack is smooth. Cause.-Too rapid cooling.

7. Sympathetic Dunts.-All ware which shows the characteristic circular hair line crack of a dunt but the entire surface of the cracked portion is not smooth are classed as sympathetic dunts. Cause.-Too weak a body: poor pugging: occluded air: careless handling.

The damaged seven inch plates, thrown out by the brushers, are inspected and sorted according to the above classification. The number in each of the seven groups is counted and recorded as percentages of the total number of plates brushed.

But such data would be of very little value unless we had some way of knowing when we were having an excessive loss from one of the above causes. This brings us to the consideration of the normal percentage for each of the above classifications.

Normal Percentages. - The normal percentages which we found to apply to our factory conditions during 1919, 1920 and the first half of 1921 are given in the following table.

The method used in obtaining these figures was as follows: Over 10,000 damaged seven inch plates, taken from burns in which the loss was normal, were inspected and classified, the average figure taken ${ }^{-}$as the normal. 
These normal percentages are nothing more or less than a guide by which we are able to tell when we have an abnormal loss in any one of the above groups, and thereby determine the cause in the shortest possible time.

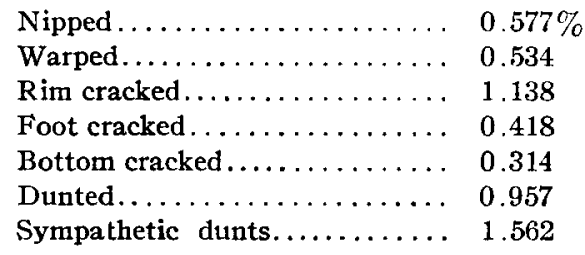

An analysis of the damaged seven inch plates from a given burn is as follows:

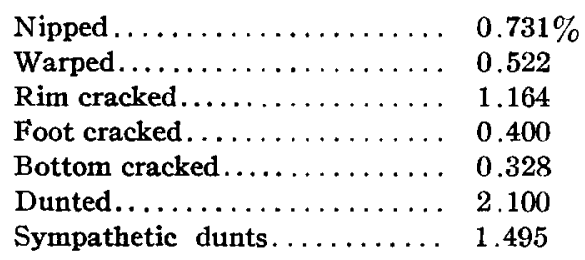

By comparison against the normal percentages, it is seen that the percentages of nipped ware and dunted ware are too high in this burn.

It must be remembered that the above normal percentages apply only to the conditions under which they were obtained, and may not apply to any other factory. As a matter of fact conditions in the same plant may be so changed as to materially affect these normal figures as was the case during the last half of 1921 , when a radical change was made in the body composition. The normal percentages in use now with this new body are as follows:

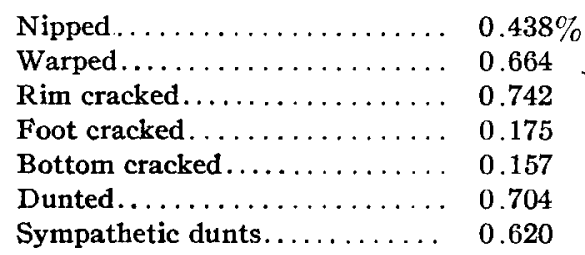

Comparison of these normal percentages with the former set shows that by increasing the strength of the body in the clay the percentage of nipped and cracked ware is decreased but the percentage of warped ware is increased. The decrease in percentage of dunted ware was due to a decrease in the cooling time.

The purpose of the biscuit loss analysis is to determine as quickly as possible the cause of high losses which are common to all classes of ware, 
and apply the cure before they become chronic. This analysis will not take care of the special causes of damaged ware which may be local and found in one class of ware only.

Analysis of the Brushers Report.-In order to make the control of the biscuit losses complete there must be some means of watching the peaks in the daily losses, and decrease them before they become general. The brushers report is excellent for this purpose, but it is necessary to have the percentages of loss of each class of ware brushed figured and ready for study by $9 \mathrm{~A}$. M. of the day following date of report. Unless the percentage of loss of all damaged ware is figured each day, it is useless as a guide for control.

All damaged ware sorted out one day should be ready for inspection on the following day. Then if a given class of ware shows an abnormal loss, the damaged ware is available for inspection and study.

\section{Summary}

The chief factor in the control of the biscuit losses is the transverse strength of the body in the clay state. If the modulus of rupture is maintained at 280 pounds per square inch the effect of careless handling of the ware is offset, and the Human Element automatically controlled. The effect of the Human Element is also made less effective by not taking the ware off of the molds until it is bone dry.

A daily analysis of the damaged seven inch plates will give early indications of such chronic troubles as, too weak a body, careless handling, improper firing, or too rapid cooling of the kilns.

Special losses such as edge cracks, cup handles coming off, etc., can best be detected and controlled from an analysis of the brushers report.

The writer acknowledges his indebtedness to Mr. C. L. Sebring for advice and assistance in this investigation.

Singring Pottery Co.

Sit Bring, OHho 